\title{
NOTE
}

\section{Precise determination of PGE in a GSJ reference sample JP-1 by ID-ICPMS after nickel sulfide fire assay preconcentration}

\author{
NaOki Shirai, Tomoe Nishino, Xiaolin Li, Hiroshi AmakaWA* and Mitsuru Ebihara \\ Department of Chemistry, Graduate School of Science, Tokyo Metropolitan University, \\ Hachioji, Tokyo 192-0397, Japan
}

(Received October 28, 2002; Accepted February 17, 2003)

\begin{abstract}
All platinum group element (PGE) abundances of a standard rock JP-1 are determined by isotope dilution method (for $\mathrm{Ru}, \mathrm{Pd}, \mathrm{Os}$, Ir and $\mathrm{Pt}$ ) and external calibration method (only for Rh) using ICP-MS combined with a fire assay preconcentration technique. The errors range $13-25 \%(2 \sigma ; n=5)$, which are comparable with those by the similar methods combined with chemical separation of PGE (Pearson and Woodland, 2000; Meisel et al., 2001).

Large deviations between our data and preferable values proposed by the Geological Survey of Japan (GSJ) are observed for Os and Ir. The scattered Os data might be indicative of heterogeneity of Os in JP1. From various viewpoints, it seems likely that our Ir data are much more reliable than the preferable values proposed by GSJ.
\end{abstract}

\section{INTRODUCTION}

The platinum group elements (PGE) include six transition metals, i.e., $\mathrm{Ru}, \mathrm{Rh}, \mathrm{Pd}$, Os, Ir and Pt. On the earth, due to the nature of chemical partitioning, these elements are distinctively depleted in the crust material. On the other hand, most meteorites are enriched in the PGE compared with the crust. Consequently, PGE abundances have been utilized for the index of the cosmic input signature (Alvarez et al., 1980; Esser and Turekian, 1988; Ebihara and Miura, 1996) to surface of the earth. Recently, PGE abundances are also utilized for testifying "late veneer" accretion (Snow and Schmidt, 1998). However, before 90's, the application of PGE to geochemical studies had been quite limited because of analytical difficulties due to their extremely low concentration (mostly in ppb or lower).

The recent progress in mass spectrometer opens the door for the "PGE geochemistry". Due to the development of the negative thermal ionization mass spectrometry (NTIMS) (Creaser et al., 1991; Volkening et al., 1991), Os emerged as a versatile isotopic tracer in various geochemical and cosmochemical issues. As for the other PGE, ICP-MS combined with fire assay technique is one of the most convenient methods for abundance determination. This method has a potential for the simultaneous determination of all PGE in a single measurement. One of the most popular preconcentration procedures along this method is Te coprecipitation after the NiS fire assay (Jackson et al., 1990; Oguri et al., 1999; Gros et al., 2002). However, since this method usually does not use any stable isotope spikes, the complete recovery is required. If isotope dilution technique (ID) is employed, the NiS fire assay technique is expected to give high quality PGE data regardless of chemical recovery. Ravizza and Pyle (1997) did the pio-

*Corresponding author (e-mail: amakawa@comp.metro-u.ac.jp) 
neering work to combine the fire assay and IDICP-MS for determining PGE (Os, Ir, Pt and Ir) in geological samples.

However, so far, there have been few available data sets covering all six PGE using ICP-MS. Data on Os and $\mathrm{Rh}$ are generally missing because of analytical difficulties (for instance, insufficient achievement of isotope equilibrium and incomplete chemical separation etc. for Os and inability to apply ID due to mono-isotopic element nature and low abundance for Rh). With Os and Rh data, we could further go into the details of mutual fractionation of PGE during various geological processes, such as weathering and planetary differntiation, and of identifying the group of meteorites, which impacted during the K-T period. Namely, the geochemical/cosmochemical application of PGE abundances must be extended as a "fingerprint" like REE. Actually, based on PGE data, McDonald et al. (2001) recently reported that the projectile, which stuck at the Morokmeng impact crater formed at the Jurassic-Cretaceous boundary, was probably an ordinary chondrite (McDonald et al., 2001). However, as pointed out by Schmidt et al. (1997) and Schmitz et al. (2001), the problem in uncertainties of PGE abundances in meteorites still remains.

The aim of this paper is to report whole PGE data including Os and Rh of JP-1, a reference sample issued from the Geological Survey of Japan (GSJ), by ICP-MS (ID-ICP-MS for five multi-isotope elements and calibration line method for Rh) to evaluate the quality of our data. We employ the fire assay preconcentration technique developed by Li et al. (1996), which was initially employed in neutron activation analysis.

\section{Analytical Method}

The sample used in this study is a standard rock sample JP-1, which is distributed from GSJ. JP-1 is a peridotite collected at Horoman in the Hokkaido Island in Japan and expected to show high PGE concentration (1-10 ppb) (Imai et al., 1995). Recently, Suzuki and Tatsumi (2001) reported Os concentration and isotopic ratio data of
JP-1. As for Ir, Pd, Ru and Pt, only the preferable values based on two data sets are proposed (Imai et al., 1995), and none for Rh.

The fire assay technique for PGE preconcentration is almost identical with that of Li and Ebihara (2003), a modified technique of Li et al. (1996). A fusion mixture of the following composition is added to $5 \mathrm{~g}$ of JP-1 powder: sodium tetraborate $10 \mathrm{~g}$, sodium carbonate $5 \mathrm{~g}$, nickel powder $0.5 \mathrm{~g}$, sulphur $0.3 \mathrm{~g}$, silica $1 \mathrm{~g}$ and mixture of PGE enriched spike $\left({ }^{100} \mathrm{Ru},{ }^{105} \mathrm{Pd}\right.$, ${ }^{189} \mathrm{Os},{ }^{191} \mathrm{Ir}$ and ${ }^{196} \mathrm{Pt}$ ). The fusion mixture and sample are thoroughly mixed and then transferred into a china crucible. The fusion is carried out for 20 minutes at $850^{\circ} \mathrm{C}$ followed by 20 minutes at $1000^{\circ} \mathrm{C}$ in an electrical furnace. After the fusion is done, the NiS button is separated from the slag. The button is crushed and heated with $6 \mathrm{M} \mathrm{HCl}$ to dissolve NiS. Subsequently, the solution is passed through a $0.2 \mu \mathrm{m}$ PTFE membrane filter to separate a precipitate, which contains PGE. The precipitate is dissolved in $6 \mathrm{M} \mathrm{HCl}$ with hydrogen peroxide. After the complete dissolution, internal standards (In and $\mathrm{Tl}$ ) for $\mathrm{Rh}$ measurement are added. The final solution is prepared by diluting to $25 \mathrm{ml}$ and afforded for the isotopic analysis.

Every set of analysis (typically four samples), we prepare procedure blanks, which are processed identically with the samples.

The isotopic analyses are performed by ICPMS (VG Plasma Quad3). For isotope dilution method, we determine following isotopic ratios: ${ }^{100} \mathrm{Ru} /{ }^{101} \mathrm{Ru},{ }^{105} \mathrm{Pd} /{ }^{106} \mathrm{Pd},{ }^{189} \mathrm{Os} /{ }^{190} \mathrm{Os},{ }^{191} \mathrm{Ir} /{ }^{193} \mathrm{Ir}$ and ${ }^{196} \mathrm{Pt} /{ }^{195} \mathrm{Pt}$. As for $\mathrm{Rh}$, a mono-isotopic element $\left({ }^{103} \mathrm{Rh}\right)$, we use an external calibration method using Rh standard solutions with In and Tl internal standards for abundance determination. We also apply the calibration method for the other PGE to monitor recovery of each element (calibration method data/ID data).

Several possible isobaric interferences are summarized in Table 1 ( $\mathrm{Pb}$ solution analysis indicates that there is no ${ }^{206} \mathrm{~Pb}$ double charge ion interference on mass number 103). Based on Table 1 , we correct the isobaric interferences for $\mathrm{Ru}, \mathrm{Rh}$ and $\mathrm{Pd}$ isotopes, measuring $\mathrm{Ni}, \mathrm{Cu}, \mathrm{Zn}, \mathrm{Zr}$, Mo 
Table 1. Isobaric interferences on PGE isotopes

\begin{tabular}{ll}
\hline Isotopes & Interferences \\
\hline${ }^{100} \mathrm{Ru}$ & ${ }^{100} \mathrm{Mo},{ }^{65} \mathrm{Cu}^{35} \mathrm{Cl},{ }^{63} \mathrm{Cu}^{37} \mathrm{Cl},{ }^{60} \mathrm{Ni}^{40} \mathrm{Ar},{ }^{62} \mathrm{Ni}^{38} \mathrm{Ar},{ }^{64} \mathrm{Ni}^{36} \mathrm{Ar},{ }^{64} \mathrm{Zn}{ }^{36} \mathrm{Ar}$ \\
${ }^{101} \mathrm{Ru}$ & ${ }^{64} \mathrm{Ni}^{37} \mathrm{Cl},{ }^{64} \mathrm{Zn}^{37} \mathrm{Cl},{ }^{66} \mathrm{Zn}^{35} \mathrm{Cl},{ }^{61} \mathrm{Ni}^{40} \mathrm{Ar},{ }^{63} \mathrm{Cu}^{38} \mathrm{Ar},{ }^{65} \mathrm{Cu}^{36} \mathrm{Ar}$ \\
${ }^{103} \mathrm{Rh}$ & ${ }^{66} \mathrm{Zn}^{37} \mathrm{Cl},{ }^{68} \mathrm{Zn}^{35} \mathrm{Cl},{ }^{63} \mathrm{Cu}^{40} \mathrm{Ar},{ }^{65} \mathrm{Cu}^{38} \mathrm{Ar},{ }^{67} \mathrm{Zn}^{36} \mathrm{Ar}$ \\
${ }^{105} \mathrm{Pd}$ & ${ }^{68} \mathrm{Zn}^{37} \mathrm{Cl},{ }^{70} \mathrm{Zn}^{35} \mathrm{Cl}^{65} \mathrm{Cu}^{40} \mathrm{Ar},{ }^{67} \mathrm{Zn}^{38} \mathrm{Ar}$ \\
${ }^{106} \mathrm{Pd}$ & ${ }^{106} \mathrm{Cd},{ }^{90} \mathrm{Zr}^{16} \mathrm{O},{ }^{66} \mathrm{Zn}^{40} \mathrm{Ar},{ }^{68} \mathrm{Zn}^{38} \mathrm{Ar},{ }^{70} \mathrm{Zn}^{36} \mathrm{Ar}$ \\
${ }^{189} \mathrm{Os}$ & non \\
${ }^{190} \mathrm{Os}$ & ${ }^{190} \mathrm{Pt}$ \\
${ }^{191} \mathrm{Ir}$ & non \\
${ }^{193} \mathrm{Ir}$ & non \\
${ }^{195} \mathrm{Pt}$ & non \\
${ }^{196} \mathrm{Pt}$ & non \\
\hline
\end{tabular}

and Cd standard solutions during sample analysis. The corrections of isobaric interferences are performed for both samples and procedure blanks. The contributions of isobaric interferences to the samples are ${ }^{100} \mathrm{Ru}, 10-25 \%$ (mainly ${ }^{100} \mathrm{Mo}$ ); ${ }^{101} \mathrm{Ru}$; less than $1 \% ;{ }^{103} \mathrm{Rh}$; less than $1 \% ;{ }^{105} \mathrm{Pd}$, less than $1 \%$; ${ }^{106} \mathrm{Pd} ; 5-40 \%$ (mainly ${ }^{90} \mathrm{Zr}^{16} \mathrm{O}$ ). Then, the real counts of samples are obtained by subtracting the procedure blanks from the samples. Relative procedural blank corrections for PGE are Ru, less than $2 \%$; Rh, less than 1\%; Pd, 2-4\%; Os, less than $3 \%$; Ir, less than $1 \%$; and Pt, 2-5\%. Finally, the calculated isotopic ratios are further corrected for the mass discrimination using the PGE standard solutions.

The Rh data are corrected for recovery, which is assumed to be same as the averaged recovery of $\mathrm{Ru}, \mathrm{Pd}, \mathrm{Pt}$ and $\mathrm{Ir}$ (more than $85 \%$ in most cases). As for $\mathrm{Ru}, \mathrm{Pd}$ and $\mathrm{Pt}$, we have tried cross-checking of data using various sets of isotopic ratios obtained by reanalyzing JP-1 (3) and (4): Ru, ${ }^{100} \mathrm{Ru} /{ }^{101} \mathrm{Ru},{ }^{100} \mathrm{Ru} /{ }^{99} \mathrm{Ru}$; Pd, ${ }^{105} \mathrm{Pd} /{ }^{106} \mathrm{Pd},{ }^{105} \mathrm{Pd} /$ ${ }^{108} \mathrm{Pd}$; $\mathrm{Pt},{ }^{196} \mathrm{Pt} /{ }^{194} \mathrm{Pt},{ }^{196} \mathrm{Pt} /{ }^{195} \mathrm{Pt}$, and ${ }^{196} \mathrm{Pt} /{ }^{198} \mathrm{Pt}$. All the elements show good internally consistent results, which agree within $4 \%$. Further detailed analytical procedure will be reported elsewhere.

\section{RESULTS AND DISCUSSION}

The PGE concentrations of JP- 1 are shown in Table 2 together with the previously reported data. The average and error of replicate analyses are also shown. The errors of each measurement are less than $5 \%$ in most cases.

The 2sigma-error/average (\%) of PGE range $13-25 \%$, which are comparable with those for the PGE analyses of reference materials reported by Pearson and Woodland (2000) and Meisel et al. (2001), both of which are employing solvent extraction/anion exchange separation techniques after acid digestion. Taking into the consideration that we do not separate any coexisting elements, such as $\mathrm{Zr}$ and $\mathrm{Hf}$, we believe that the reproducibility of our analyses is satisfactory.

Only few data are available for PGE in JP-1 and do not necessarily show good agreement with our data. Between our data and the GSJ preferable values, $\mathrm{Ru}$ and Pd show good agreement, but Os and Ir do not.

Suzuki and Tatsumi (2001) recently reported the Os isotopic ratio and concentration of JP-1. Although the duplicate isotopic analyses show almost identical values, the duplicate concentration analyses differ in $10 \%$. They suggested that the heterogeneous distribution of Os in sample resulted in such difference in concentration. Our data are 40 to $60 \%$ higher than those of Suzuki and Tatsumi (2001).

One of the possible explanations for the difference between our data and those by Suzuki and Tatsumi (2001) is the preferential loss of spike Os. The fire assay technique used in this study might be more prone to the loss of spike Os than the Carius tube method employed by Suzuki and 
Table 2. PGE concentrations of JP-1 (ppb)

\begin{tabular}{|c|c|c|c|c|c|c|}
\hline & Os & Ir & $\mathrm{Ru}$ & $\mathrm{Rh}$ & $\mathrm{Pt}$ & $\mathrm{Pd}$ \\
\hline JP-1(1) & $3.49 \pm 0.05$ & $3.05 \pm 0.10$ & $5.62 \pm 0.05$ & $0.844 \pm 0.019$ & $3.67 \pm 0.12$ & $1.28 \pm 0.03$ \\
\hline JP-1(2) & $3.95 \pm 0.16$ & $3.56 \pm 0.21$ & $5.95 \pm 0.14$ & $0.775 \pm 0.005$ & $3.79 \pm 0.09$ & $1.21 \pm 0.02$ \\
\hline JP-1(3) & $4.03 \pm 0.06$ & $3.12 \pm 0.05$ & $6.31 \pm 0.08$ & $0.819 \pm 0.009$ & $3.80 \pm 0.11$ & $1.35 \pm 0.06$ \\
\hline JP-1(4) & $3.75 \pm 0.16$ & $3.35 \pm 0.05$ & $6.00 \pm 0.07$ & $0.926 \pm 0.026$ & $4.25 \pm 0.14$ & $1.28 \pm 0.06$ \\
\hline JP-1(5) & $4.82 \pm 0.10$ & $3.48 \pm 0.07$ & $7.00 \pm 0.09$ & $1.010 \pm 0.020$ & $4.44 \pm 0.07$ & $1.51 \pm 0.03$ \\
\hline average $(n=5)$ & 4.01 & 3.31 & 6.18 & 0.875 & 3.99 & 1.33 \\
\hline error (1sigma) & 0.50 & 0.22 & 0.52 & 0.093 & 0.33 & 0.11 \\
\hline 2sigma/average (\%) & 24.9 & 13.4 & 16.9 & 21.4 & 16.8 & 17.2 \\
\hline GSJ preferable value & 7.9 & 2.0 & 6.5 & - & 4.9 & 1.3 \\
\hline Suzuki and Tatsumi (2001) & $2.44,2.71$ & - & - & - & - & - \\
\hline
\end{tabular}

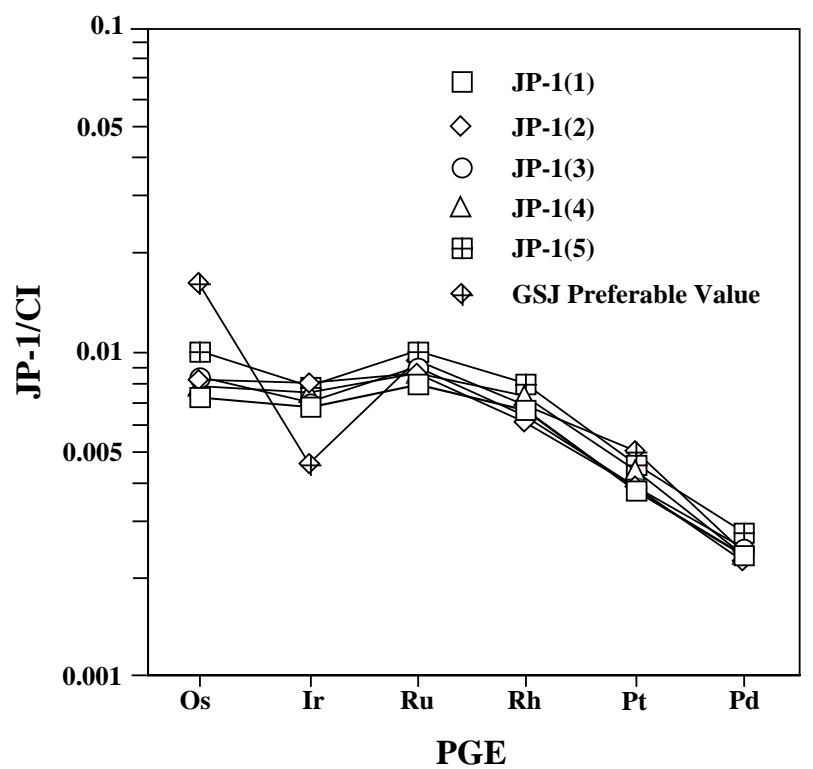

Fig. 1. CI-normalized PGE patterns of JP-1. The concentrations of CI chondrites are from McDonough and Sun (1995).

Tatsumi (2001). If the preferential loss of spike solution could occur, it would result in erroneous high Os concentration. From following reasons, however, we will deny a possibility of the preferential loss of spike Os in our sample. PGE in the Allende meteorite of different samples amounts (5 20 mg) were determined by using the same procedure and Os concentration, $892 \pm 14 \mathrm{ppb}$ ( $n=3$; Nishino, 2002) was found to be consistent with literature values (830-860 ppb) (Jochum, 1996; Wolf et al., 1983). Recently, Lee (2002) compared the Os concentration data of peridotite xenoliths determined by acid digestion and by fire assay and found that most of the data agrees within $25 \%$. These facts support the reliability of our method and suggest that the difference is not due to the analytical artifacts. Although further intensive studies are required, we think that Os is highly heterogeneous in JP-1 as suggested by Suzuki and Tatsumi (2001).

The CI chondrite-normalized PGE patterns for JP-1 are plotted in Fig. 1 together with that of the 


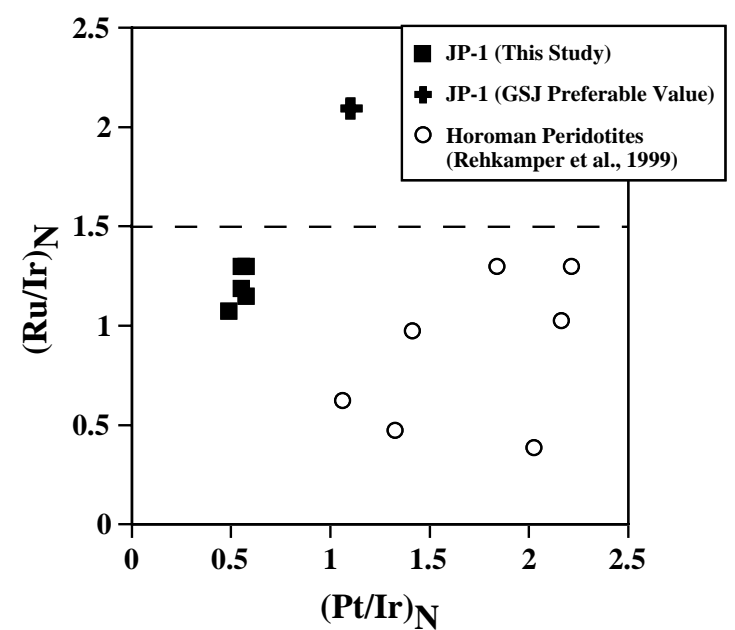

Fig. 2. Diagram of CI chondrite-normalized Pt/Ir vs. Ru/Ir. Note that the GSJ preferable data point clearly deviates from the other data.

GSJ preferable values. We arrange PGE ( $x$-axis) in the order of melting point (high to low), following Pattou et al. (1996). The clear differences in Os and Ir concentrations are observed between our data and the GSJ preferable values. First, we would like to evaluate the Ir concentrations. Rehkamper et al. (1999) reported Ir, Ru, Pt and $\mathrm{Pd}$ concentrations of peridotites from Horoman, Japan, which is the same sampling location as that of JP-1. Figure 2 is a diagram of CI chondritenormalized Pt/Ir vs. Ru/Ir of JP-1 and the Horoman peridotites analyzed by Rehkamper et al. (1999). The GSJ preferable value point clearly deviates from both our data and the Horoman data. Although the Horoman data are scattered, Fig. 2 suggests that $(\mathrm{Ru} / \mathrm{Ir})_{\mathrm{N}}$ of the peridotites (both Horoman and JP-1) should be less than 1.5. So, our data seem to be compatible with the data of Rehkamper et al. (1999). Therefore, the GSJ preferable value seems to show too high Ru concentration or too low Ir concentration. We think that the high $\mathrm{Ru}$ concentration is improbable because the $\mathrm{Ru}$ concentration shows good agreement with our data. Furthermore, Shinozuka et al. (2003) recently report the PGE data (except for Os) of JP-1 by NiS fire assay preconcentration with Te coprecipitation technique and found that their Ir concentration is $3.4 \mathrm{ppb}$, which is almost identical with our data. Consequently, we conclude that the GSJ preferable Ir concentration must be lower than the true value. At now, our data determined by ID method seem to be the most reliable ones.

It is not easy to evaluate whether Rh data are reliable or not due to lack of any reference value. Aforementioned above we arrange the PGE as the same manner as Pattou et al. (1996) and found a smooth decrease trend from $\mathrm{Ru}$ to $\mathrm{Pd}$. This implies that $\mathrm{Rh}$ data fall on this trend and supports the reliability of our Rh data.

\section{SUMMARY}

We determined all the PGE of JP-1 issued from GSJ using ID-ICP-MS combined with fire assay technique. Compared our data with the preferable data proposed by GSJ, the large deviations are observed for Os and Ir. The Os data also deviate from those reported by Suzuki and Tatsumi (2001). These observations suggest that Os is highly heterogeneous in JP-1. On the other hand, as for Ir, various evidences indicate that our data are much more reliable than the preferable value. The smooth PGE patterns from Ru to Pd might verify our Rh data.

Acknowledgments-We would like to thank for B. Peuker-Ehrenbrink and K. Suzuki for providing useful and constructive comments on the manuscript. This study was partially supported by the Ministry of Education, Culture, Sports, Science and Technology under Grants-in-Aid No. 11440167 to Tokyo Metropolitan University (M. Ebihara, principal investigator).

\section{REFERENCES}

Alvarez, L. W., Alvarez, W., Asaro, F. and Michel, H. V. (1980) Extraterrestrial cause for the CretaceousTertiary extinction. Science 208, 1095-1108.

Creaser, R. A., Papanastassiou, D. A. and Wasserburg, G. J. (1991) Negative thermal ion mass spectrometry of osmium, rhenium and iridium. Geochim. Cosmochim. Acta 55, 397-401.

Ebihara, M. and Miura, T. (1996) Chemical characteristics of the Cretaceous-Tertiary boundary layer at Gubbio, Italy. Geochim. Cosmochim. Acta 60, 51335144. 
Esser, B. K. and Turekian, K. K. (1988) Accretion rate of extraterrestrial particles determined from osmium isotope systematics of Pacific clay and manganese nodules. Geochim. Cosmochim. Acta 52, 1383-1388.

Gros, M., Lorand, J.-P. and Luguet, A. (2002) Analysis of platinum group elements and gold in geological materials using NiS fire assay and Te coprecipitation; the NiS dissolution step revisited. Chem. Geol. 185, 179-190.

Imai, N., Terashima, S., Itoh, S. and Ando, A. (1995) 1994 compilation values for GSJ reference samples "Igneous rock series". Geochem. J. 29, 91-95.

Jackson, S. E., Freyer, B. J., Gosse, W. D., Healey, C. H., Longerich, P. and Strong, D. F. (1990) Determination of the precious metals in the geological materials by inductively coupled plasma-mass spectrometry (ICP-MS) with nickel-sulphide fireassay collection and tellurium coprecipitation. Chem. Geol. 83, 119-132.

Jochum, K. P. (1996) Rhodium and other platinumgroup elements in carbonaceous chondrites. Geochim. Cosmochim. Acta 60, 3353-3357.

Lee, C.-T. A. (2002) Platinum-group element geochemistry of peridotite xenoliths from the Sierra Nevada and the Basin and Range, California. Geochim. Cosmochim. Acta 66, 3987-4005.

Li, X. L. and Ebihara, M. (2003) Determination of all platinum-group elements in mantle-derived xenoliths by neutron activation analysis with NiS fire-assay preconcentration. J. Radioanal. Nucl. Chem. 255, 131-135.

Li, X. L., Tong, C., Zhu, J. and Wang, Y. (1996) Determination of platinum group elements in four new reference samples of marine sediments and nodules by neutron activation analyses after nickel sulphide fire assay preconcentration. Geostand. Newslett. 20, 263265.

McDonald, I., Andreoli, M. A. G., Hart, R. J. and Tredoux, M. (2001) Platinum-group elements in the Morokweng impact structure, South Africa: evidence for the impact of a large ordinary chondrite projectile at the Jurassic-Cretaceous boundary. Geochim. Cosmochim. Acta 65, 299-309.

McDonough, W. F. and Sun, S.-s. (1995) The composition of the Earth. Chem. Geol. 120, 223-253.

Meisel, T., Moser, J., Fellner, N., Wegscheider, W. and Schoenberg, R. (2001) Simplified method for the determination of $\mathrm{Ru}, \mathrm{Pd}, \mathrm{Re}, \mathrm{Os}, \mathrm{Ir}$ and $\mathrm{Pt}$ in chromites and other geological materials by isotope dilution ICP-MS and acid digestion. Analyst 126, 322-328.

Nishino, T. (2002) Determination of platinum group elements abundances in rock samples by isotope dilution ICP-MS. Master Thesis, Tokyo Metropolitan
University, 63 pp. (in Japanese).

Oguri, K., Shimoda, G. and Tatsumi, Y. (1999) Quantitative determination of gold and platinum-group elements in geological samples using NiS fire-assay and tellurium coprecipitation with inductively coupled plasma-mass spectrometry (ICP-MS). Chem. Geol. 157, 189-197.

Pattou, L., Lorand, J. P. and Gros, M. (1996) Nonchondritic platinum-group element ratios in the Earth's mantle. Nature 379, 712-715.

Pearson, D. G. and Woodland, S. J. (2000) Solvent extraction/anion exchange separation and determination of PGEs (Os, Ir, Pt, Pd, Ru) and Re-Os isotopes in geological samples by isotope dilution ICP-MS. Chem. Geol. 165, 87-107.

Ravizza, G. and Pyle, D. (1997) PGE and Os isotopic analyses of single sample aliquots with NiS fire assay preconcentration. Chem. Geol. 141, 251-268.

Rehkamper, M., Halliday, A. N., Alt, J., Finton, J. G., Zipfel, J. and Takazawa, E. (1999) Non-chondritic platinum element ratios in oceanic mantle lithosphere: petrogenetic signature of melt percolation? Earth Planet. Sci. Lett. 172, 65-81.

Schmidt, G., Palme, H. and Kratz, K.-L. (1997) Highly siderophile elements ( $\mathrm{Re}, \mathrm{Os}, \mathrm{Ir}, \mathrm{Ru}, \mathrm{Rh}, \mathrm{Pd}, \mathrm{Au}$ ) in impact melts from three European impact craters (Saaksjarvi, Mien, and Dllen): clues to the nature of the impacting bodies. Geochim. Cosmochim. Acta 61 , 2977-2987.

Schmitz, B., Tassinari, M. and Peuker-Ehrenbrink, B. (2001) A rain of ordinary chondritic meteorites in the early Ordovician. Earth Planet. Sci. Lett. 194, $1-15$.

Shinozuka, K., Suzuki, K. and Tatsumi, Y. (2003) Determination of platinum group elements using preconcentration by nickel sulfide fire assay, followed by tellurium coprecipitation. Frontier Research on Earth Evolution, Volume 1, IFREE REPORT for 2001-2002 (in press).

Snow, J. E. and Schmidt, G. (1998) Constraints on earth accretion deduced from noble metals in the oceanic mantle. Nature 391, 166-169.

Suzuki, K. and Tatsumi, Y. (2001) Osmium concentrations and ${ }^{187} \mathrm{Os} /{ }^{188} \mathrm{Os}$ ratios of GSJ reference samples, JB-1a, JA-2 and JP-1. Geochem. J. 35, 207210 .

Volkening, J., Walczyk, T. and Heumann, K. G. (1991) Os isotope ratio determinations by negative thermal ionization mass spectrometry. Int. J. Mass Spectrom. Ion Processes 105, 147-159.

Wolf, R., Ebihara, M., Richter, G. R. and Anders, E. (1983) Aubrites and diogenites: trace element clues to their origin. Geochim. Cosmochim. Acta 47, 22572270 . 